\title{
BMJ Open Experiences of women with cardiac disease in pregnancy: a systematic review and metasynthesis
}

\author{
Angela J Dawson, ${ }^{1}$ Yordanka Krastev, ${ }^{1,2}$ William A Parsonage, ${ }^{3,4}$ Michael Peek, ${ }^{5,6}$ \\ Karin Lust, ${ }^{7}$ Elizabeth A Sullivan ${ }^{1}$
}

To cite: Dawson AJ, Krastev Y, Parsonage WA, et al. Experiences of women with cardiac disease in pregnancy: a systematic review and metasynthesis. BMJ Open 2018;8:e022755. doi:10.1136/ bmjopen-2018-022755

- Prepublication history and additional material for this paper are available online. To view these files, please visit the journal online (http://dx.doi. org/10.1136/bmjopen-2018022755).

Received 8 March 2018

Revised 3 July 2018

Accepted 9 August 2018

Check for updates

(c) Author(s) (or their employer(s)) 2018. Re-use permitted under CC BY-NC. No commercial re-use. See rights and permissions. Published by BMJ.

For numbered affiliations see end of article.

Correspondence to

Professor Elizabeth A Sullivan; elizabeth.sullivan@uts.edu.au

\section{ABSTRACT}

Objective Cardiac disease in pregnancy is a leading cause of maternal death in high-income countries. Evidence-based guidelines to assist in planning and managing the healthcare of affected women is lacking. The objective of this research was to produce the first qualitative metasynthesis of the experiences of pregnant women with existing or acquired cardiac disease to inform improved healthcare services.

Method We conducted a systematic search of peerreviewed publications in five databases to investigate the decision-making processes, supportive strategies and healthcare experiences of pregnant women with existing or acquired cardiac disease, or of affected women contemplating pregnancy. Identified publications were screened for duplication and eligibility against selection criteria, following Preferred Reporting Items for Systematic Reviews and Meta-Analyses guidelines. We then undertook a thematic analysis of the data relating to women's experiences extracted from each publication to inform new healthcare practices and communication.

Results Eleven studies from six countries were included in our meta-synthesis. Four themes were revealed. Women with congenital and acquired heart disease identified situations where they had either taken charge of decision-making, lacked control or experienced emotional uncertainty when making decisions. Some women were risk aware and determined to take care of themselves in pregnancy while others downplayed the risks. Women with heart disease acknowledged the importance of specific social support measures during pregnancy and after child birth, and reported a spectrum of healthcare experiences. Conclusions There is a lack of integrated and tailored healthcare services and information for women with cardiac disease in pregnancy. The experiences of women synthesised in this research has the potential to inform new evidencebased guidelines to support the decision-making needs of women with cardiac disease in pregnancy. Shared decisionmaking must consider communication across the clinical team. However, coordinated care is challenging due to the different specialists involved and the limited clinical evidence concerning effective approaches to managing such complex care.

\section{INTRODUCTION}

Cardiac disease in pregnancy is a leading cause of maternal death in the developed

\section{Strengths and limitations of this study}

This is the first metasynthesis of qualitative research that investigated the experiences of pregnant women with a spectrum of cardiac disease.

- The small number of studies in this synthesis demonstrated the paucity of qualitative research in this area, particularly the voices of pregnant women with genetic conditions

- The thematic analysis enabled patterns to be discerned that could be translated to cardiac disease in pregnancy and potentially other rare and chronic diseases in pregnancy.

- Our multidisciplinary research team enabled a rich and detailed yet complex account of the extracted data.

world. In the USA, pregnancy-related deaths due to cardiovascular disease were ranked as the leading category of death from 2011 to 2013 at $15.5 \% .^{1}$ In the $\mathrm{UK}$, the rate of maternal deaths associated with cardiac disease more than doubled from 1.0 in 1985 to 2.3 per 100000 maternities in $2008 .^{2}$ In Australia, cardiac disease in pregnancy has been the leading cause of indirect maternal deaths for almost 50 years, ${ }^{34}$ and a common cause of late maternal death. ${ }^{45}$

Cardiac disease in pregnancy constitutes a broad spectrum of conditions, including congenital heart diseases (eg, ventricular septal defect, transposition of the great vessels), genetic heart diseases (eg, hypertrophic cardiomyopathy, long QT syndrome, Brugada syndrome), chronic arrhythmia conditions (eg, Wolff-Parkinson-White syndrome), as well as heart diseases acquired before or during pregnancy (eg, rheumatic heart disease, ischaemic heart disease, peripartum cardiomyopathy (PPCM) ). Heart transplants can also affect pregnancy outcomes.

Cardiac disease in pregnancy is associated with high rates of morbidity and hospitalisation. For example, $15 \%$ of women in Europe have been admitted for cardiac indications 
during pregnancy. ${ }^{6}$ Approximately one in four women with cardiac disease in pregnancy are hospitalised during pregnancy, and overall cardiac disease in pregnancy is associated with the increased likelihood of eclampsia, caesarean birth and postpartum haemorrhage. ${ }^{6}$ For the baby, there is an increased likelihood of stillbirth, preterm birth and acquired congenital disease. ${ }^{6}$ The European Registry of Pregnancy and Cardiac Disease has reported significant adverse perinatal outcomes for both mother and baby, most notably a maternal mortality rate of $1 \%$, which is more than 100 times the rate for women without cardiac disease.

Confidential death enquiry data from the UK suggest there are an increasing number of women who die from the combination of pregnancy and cardiac disease. ${ }^{2}$ There are several possible explanations for this observation, including the improved survival ( 90\%) of children with congenital heart disease to adulthood, increased awareness and diagnosis of genetic conditions, lifestyle factors (eg, obesity) and older maternal age associated with ischaemic heart disease. ${ }^{7-9}$

Many women with cardiac disease have been found to have high rates of unintended pregnancies that may reflect the availability and acceptability of and access to pre-conception and pregnancy counselling by healthcare professionals, as well as gaps in women's contraceptive knowledge and decision making support. ${ }^{11}$ Despite clinical available guidelines, ${ }^{12-14}$ limited knowledge exists regarding the healthcare, support and decision-making experiences of women with cardiac disease who are pregnant, or contemplating pregnancy. Insights into women's experiences of planning and undergoing pregnancy including their perceptions and satisfaction are critical to the provision of health services, care and information.

This paper aims to synthesise qualitative healthcare evidence to deliver new insights to best support decision-making for women with cardiac disease and for healthcare professionals to improve their quality of cardiac care from preconception planning to the postnatal period.

\section{METHODS}

\section{Data sources and search strategy}

We undertook a qualitative systematic review of the literature and conducted a meta-analysis following methods outlined by Thomas and Harden ${ }^{15}$ to understand the healthcare experiences of pregnant women or women contemplating pregnancy with existing or acquired cardiac disease, in order to gain insights into their resilience including coping strategies.

We used the Preferred Reporting Items for Systematic Reviews and Meta-Analyses statement (figure 1) with a cut-off date of 2016. We searched the literature available in five online, bibliographic databases: CINAHL Plus (1995-October 2016), Embase (1996-October 2016), Ovid MEDLINE (1996-October2016), PsycINFO (1984October 2016) and the Joanna Briggs Institute Evidence Based Practice Database (1996-October 2016). Boolean operators (and, or, not) were used to refine our search with the following keywords: cardiac disease, pregnancy, pregnant women, decision-making and shared decision-making. Publications that met our selection criteria (table 1) were further analysed. We also searched for publications in Google Scholar and manually from the reference lists of key papers that identified an additional 19 relevant publications. See online supplementary appendix for details of the bibliographic search strategy.

\section{Quality assessment and data extraction}

Nineteen potentially relevant publications were identified. Of these, eight were excluded because they were either irrelevant or not peer-reviewed (eg, PhD thesis). Six qualitative publications and the qualitative components of five mixed methods publications were appraised using the Critical Appraisal Skills Programme (CASP) qualitative checklist ${ }^{16}$ by two authors (AD and YK). Each paper was independently assessed using a table with 10 CASP questions that analysed the data sampling, collection and analysis processes and the coherence of the paradigm underpinning the study involving the fit between the data gathered and the conceptual work of analysis and interpretation. Despite the methodological limitations of some papers, including gaps in the discussion of reflexivity and credibility, all 11 papers were included in the metasynthesis as it was deemed that their strengths outweighed these issues. Data from the findings sections of each publication that detailed the preconception planning and pregnancy experiences of women with cardiac disease were extracted for further analysis. This included direct quotes and text describing related findings.

\section{Data analysis}

The extracted text was coded 'line-by-line' by two authors $(\mathrm{AD}$ and $\mathrm{YK})$ and then descriptive categories were developed that aligned with the original studies. The concepts from the descriptive categories were grouped into themes and subthemes and conceptual links among themes were identified. Tables were used for this process. Emerging descriptor texts were highlighted in different colours in each study in each paper. These descriptors were then compared across papers and similar descriptors were synthesised into one table. This led to the conflation of descriptive themes and the development of emergent categories whose meaning was refined in order to answer the research questions and address the aim of the study. ${ }^{17}$

\section{Patient and public involvement}

Qualitative patient data were the focus of this synthesis; however, patients and the public were not involved in the design of the study or analysis of the data.

\section{RESULTS}

A summary of the methodology and findings of the 11 studies used in this study is given in table 2. The studies were conducted across six countries: USA $(n=5)$, Australia $(n=2)$, Sweden, $(n=2)$, Canada $(n=1)$, Norway 


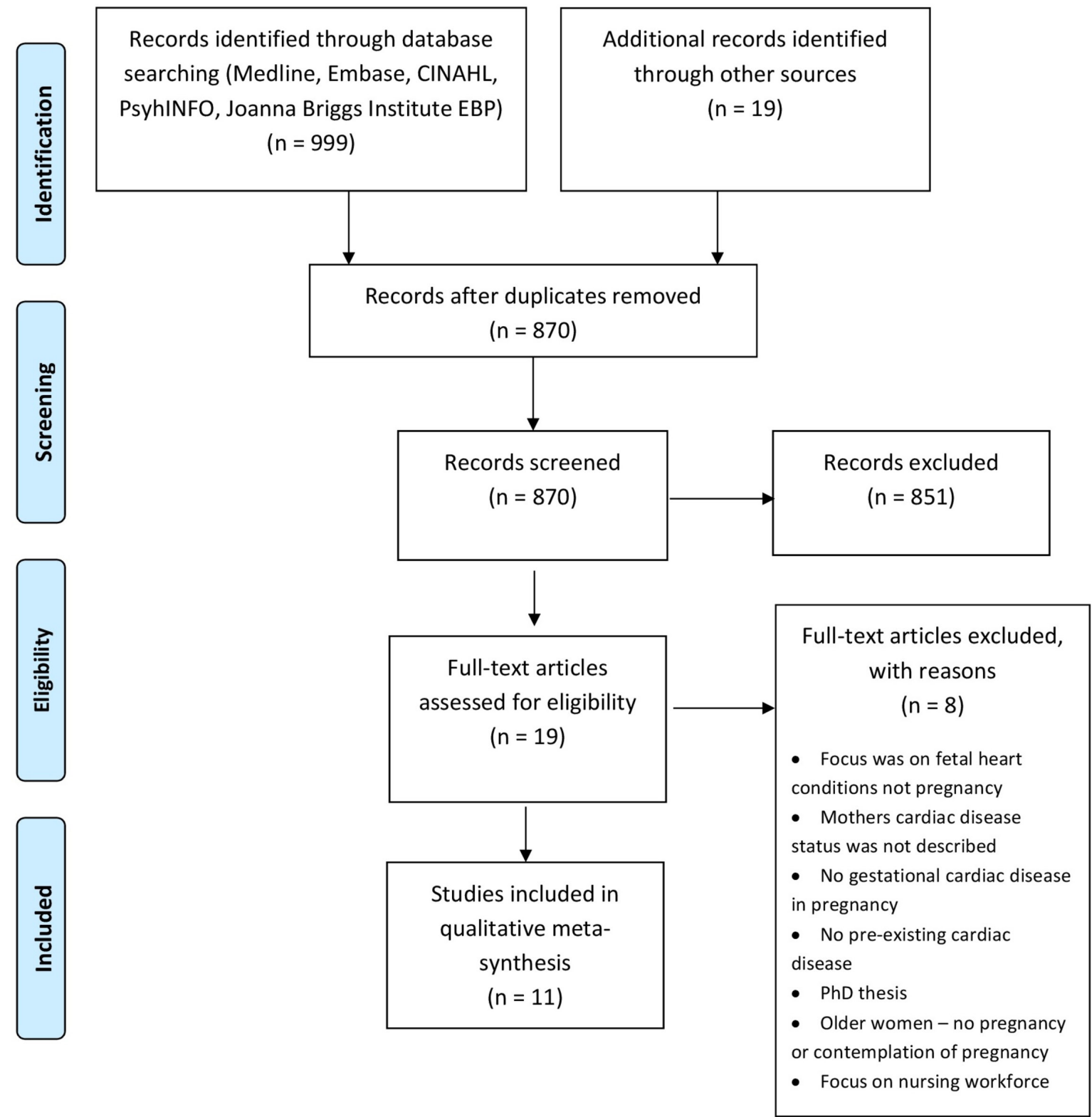

Figure 1 Preferred Reporting Items for Systematic Reviews and Meta-Analyses flowchart of cardiac disease in pregnancy.

$(\mathrm{n}=1)$ and Belgium $(\mathrm{n}=1)$. Six studies comprised qualitative designs ${ }^{18-23}$ and five used mixed methods ${ }^{24-28}$ (see table 3). There were a total of 383 women participants with the following conditions: congenital heart disease $(\mathrm{n}=81)$, PPCM $(\mathrm{n}=298)$ and long QT syndrome (see table $3 ; \mathrm{n}=4)$.

Four themes and seven subthemes emerged from our meta-analysis and are summarised in table 4 and described in more detail below.

\section{Women's autonomy and control}

Taking charge of decision-making

Some women expressed their determination to take control and make their own decisions regarding their pregnancies. One woman was resolute to try to fall pregnant and if unsuccessful wanted to consider other options: "l want to give birth to at least one child. 1 want to have the opportunity to do that, then later I can adopt
.... ${ }^{18}$ Another woman became pregnant 2 months after her diagnosis of heart disease and described being 'told to terminate her pregnancy' but she 'refused'. ${ }^{27}$ Another woman felt she 'had lived a good life' and her disease 'could not be considered a reason for terminating a pregnancy'. ${ }^{18}$ The positive thinking that 'life isn't over just because you have peripartum cardiomyopathy' and the possibility of having more children was a key factor driving the decision of women who went through another pregnancy and 'received a beautiful little girl in exchange'. ${ }^{26}$

The trust that women had in their clinicians and their experiences of successfully adapting to their congenital cardiac disease by developing coping mechanisms played a role in their desire to make their own decisions and proceed with their pregnancies. ${ }^{25}$ Some women felt that they had to take responsibility not only for their own health, but also for that of future generations. These 
Table 1 Inclusion and exclusion criteria used to identify publications that involved women with cardiac disease in pregnancy

\begin{tabular}{|c|c|}
\hline Inclusion criteria & Exclusion criteria \\
\hline $\begin{array}{l}\text { The experiences of women of } \\
\text { reproductive age with existing } \\
\text { or acquired cardiac disease } \\
\text { in pregnancy who were or } \\
\text { had been pregnant, or who } \\
\text { had contemplated pregnancy } \\
\text { (including preconception, } \\
\text { and prenatal, intrapartum, } \\
\text { perinatal and postnatal } \\
\text { periods) }\end{array}$ & $\begin{array}{l}\text { Women with cardiac disease } \\
\text { who were not of reproductive } \\
\text { age or who had not been or } \\
\text { contemplated pregnancy }\end{array}$ \\
\hline Qualitative studies & Quantitative studies \\
\hline $\begin{array}{l}\text { Mixed methods design with a } \\
\text { qualitative component }\end{array}$ & $\begin{array}{l}\text { Clinical studies of cardiac } \\
\text { disease in pregnancy }\end{array}$ \\
\hline $\begin{array}{l}\text { Published in the English } \\
\text { language }\end{array}$ & Non-English articles \\
\hline
\end{tabular}

women undertook genetic testing as early as possible ${ }^{18}$ to prevent giving birth to a child with congenital heart disease. $^{21}$

Women desired to take control and live a "normal life', 2024 participate in social activities and 'fit in' ${ }^{21}$ This often stemmed from childhood experiences of being excluded and 'feeling different'. ${ }^{21}$ For some women, this motivated them to make their own decisions and to take on new and different activities as a means of coping: 'I do these things just to challenge those boundaries, limitations'. 19

\section{A lack of control}

In contrast, a lack of autonomy and control was noted by women in relation to pregnancy decision-making. Some women believed that someone else would decide whether they should become pregnant in response to being 'told right from the beginning not to have any more children'. ${ }^{22}$ Another woman felt that she had no choice and could not take the risk and have her family shoulder the burden of another episode of heart failure. ${ }^{21}$ Others described feeling how social pressure and the judgement of others interfered with their decision to have more children: 'you're not supposed to get pregnant when you have congenital heart disease'. ${ }^{21}$ Another woman, who already had a child diagnosed with heart condition, feared being perceived as 'selfish'. 18

For some of the women, their heart disease defined and dominated their decision-making. ${ }^{18}$ One woman talked of how everything in her life 'came down to the heart'. ${ }^{21}$ While another described the tension the control of their disease had over them, and their own autonomy to make decisions, including those about pregnancy: 'I do make plans and that sort of thing, but I don't dare to carry them out. Now I understand that ...I must start something independently ...but I'm scared'. ${ }^{19}$ A lack of autonomy and control was discussed by women in relation to financial hardship. Some women said that they had registered for disability payments after their diagnosis and were concerned that they would not be able to work after giving birth and contribute to the household income due to the impact the pregnancy would have on their physical and mental health. As a result, these women felt they would be financially dependent on others. ${ }^{22}$

The emotional uncertainty of decision-making

In three studies, women described the emotional uncertainty of their preconception decision-making in highly emotional terms, where they were at a loss regarding what to do. ${ }^{1819}$ One women asked 'Is it worth it having a baby?'. ${ }^{28}$ Women expressed feelings of being depressed and devastated, and experiencing 'emotional torture' and feeling 'hysterical' when they were diagnosed with cardiac disease and advised by their doctors against future pregnancies. ${ }^{22}$ These circumstances required them to rethink their situation. ${ }^{22}$ Several women described the decisions regarding pregnancy and childbirth as extremely difficult for them ${ }^{18}$ due to uncertainty regarding the progression and prognosis of their disease. ${ }^{19}$

\section{Helplessness, fear and vulnerability}

The feeling of helplessness and loss of control in relation to the development of cardiac disease symptoms both during pregnancy, birth and postpartum was expressed by one woman as like 'being caught in a spider web', ${ }^{28}$ or being trapped by their condition and fearful about future pregnancies. ${ }^{20}$ Another woman described being pregnant as a 'constant struggle between hope and helplessness' ${ }^{28}$ There was a mix of physical and emotional symptoms when women described the suffering of their own illness and the inability to take care of their newborn baby. ${ }^{22} 23$

Women feared dying. They were deeply concerned that they would not survive the pregnancy and that they would leave their child motherless, ${ }^{212425}$ or be left disabled and unable to care for their newborn. ${ }^{24}$ They were worried about passing on heart disease to their unborn baby, ${ }^{18} 24$ giving birth to a baby with a heart abnormality ${ }^{2124}$ and the effect that medications might have on their baby. ${ }^{21}$ These fears deeply affected women and some continued to relive the distress brought on by the diagnosis of cardiac disease in pregnancy through flashbacks, years after the birth of their child. ${ }^{23}$

\section{Self-care and risk awareness in pregnancy}

Risk awareness and desire for motherhood were discussed in four of the papers. ${ }^{18242527}$ In a study by Andersen et $a l,{ }^{18}$ women with long QT syndrome reported being frustrated not to know how much danger to their health a pregnancy might impose. They felt that if they took the risk to become pregnant, the decision was theirs.

For another group of women with congenital heart disease, the determination to have a child was so strong that it outweighed self-care considerations. Despite being aware of the complications during pregnancy, 10 of the 20 women in the study perceived their disease to be less 
Table 2 Summary of the methodology and data of the 11 publications used in this review

\begin{tabular}{|c|c|c|}
\hline Publication & Method & Aim \\
\hline $\begin{array}{l}\text { Andersen et } a l,{ }^{18} \\
2008\end{array}$ & $\begin{array}{l}\text { Qualitative: in-depth, } \\
\text { face-to-face interviews }\end{array}$ & $\begin{array}{l}\text { To investigate psychosocial } \\
\text { aspects of living with long QT } \\
\text { syndrome (LQTS) } \\
\text { To identify the daily challenges and } \\
\text { coping strategies of LQTS patients } \\
\text { To describe the experience of LQTS } \\
\text { patients with healthcare services }\end{array}$ \\
\hline $\begin{array}{l}\text { Claessens et } \\
a{ }^{19}{ }^{19} 2005\end{array}$ & $\begin{array}{l}\text { Qualitative: } \\
\text { unstructured, in-depth } \\
\text { interviews }\end{array}$ & $\begin{array}{l}\text { To explore the lived experiences of } \\
\text { adult patients with congenital heart } \\
\text { disease }\end{array}$ \\
\hline
\end{tabular}

Findings

- LQTS patients were concerned that the condition would be inherited by their children and grandchildren.

- LQTS patients favoured early genetic testing for LGTS, and the provision of information about LQTS in children presented early and gradually.

- The central theme of the patients' lived experiences was 'feeling different'. Patients struggled constantly with themselves and with their environment to be accepted as normal.

\begin{tabular}{|c|c|c|}
\hline $\begin{array}{l}\text { Dekker et al, }{ }^{22} \\
2016\end{array}$ & $\begin{array}{l}\text { Publicly available } \\
\text { narratives from three } \\
\text { online support groups }\end{array}$ & $\begin{array}{l}\text { To describe the experience of } \\
\text { women diagnosed with peripartum } \\
\text { cardiomyopathy (PPCM) }\end{array}$ \\
\hline Gantt, ${ }^{21} 1992$ & $\begin{array}{l}\text { Qualitative: } \\
\text { unstructured face- } \\
\text { to-face interviews; } \\
\text { grounded theory }\end{array}$ & $\begin{array}{l}\text { To generate an understanding of, } \\
\text { and theories about, the lives of } \\
\text { women with congenital heart disease }\end{array}$ \\
\hline
\end{tabular}

Nearly $40 \%$ of women felt that they were dismissed by healthcare providers. Women had difficulty caring for their newborns during the postnatal period, and they struggled with the medical advice they received to not conceive again.

- Lack of information related to women's bodies and reproductive issues ('growing up female').

- Over involvement of mothers and healthcare professionals in the affairs of the child's and woman's body, resulting in decreased ownership of the body by the woman ('living against the body').

- Poor self-esteem, self-concept and body image ('growing up heartsick').

- A need for various types of counselling for women with congenital heart disease was identified.

\begin{tabular}{|c|c|c|c|}
\hline Gantt, ${ }^{20} 2002$ & $\begin{array}{l}\text { Qualitative: descriptive } \\
\text { with unstructured } \\
\text { interviews }\end{array}$ & $\begin{array}{l}\text { To study the effect of congenital } \\
\text { heart diseases on the mother- } \\
\text { daughter relationship }\end{array}$ & $\begin{array}{l}\text { Over-riding theme of the study was } \\
\text { normalising in the face of chronic } \\
\text { illness, with a tendency by the } \\
\text { mothers and daughters to focus on } \\
\text { their lives instead of their relationship } \\
\text { with one another. }\end{array}$ \\
\hline Hess et al, ${ }^{26} 2010$ & $\begin{array}{l}\text { Descriptive: a survey of } \\
\text { open-ended and Likert- } \\
\text { type questions }\end{array}$ & $\begin{array}{l}\text { To determine the benefits } \\
\text { of participation in the online } \\
\text { support group for peripartum } \\
\text { cardiomyopathy, based on a survey } \\
\text { of active members of the group }\end{array}$ & $\begin{array}{l}\text { One of the most important issues } \\
\text { facing women with peripartum } \\
\text { cardiomyopathy is future } \\
\text { childbearing. } \\
\text { The benefits of participation in } \\
\text { the online support group included } \\
\text { obtaining and sharing information, } \\
\text { exchanging stories, being understood } \\
\text { by other women and reassurance. }\end{array}$ \\
\hline
\end{tabular}


Table 2 Continued

\begin{tabular}{lll}
\hline Publication & Method & Aim \\
\hline Ngu et al, ${ }^{25} 2014$ & $\begin{array}{l}\text { Mixed method: } \\
\text { retrospective and }\end{array}$ & To assess the perceptions of women \\
& descriptive & with congenital heart disease \\
& regarding the severity of their cardiac \\
& abnormality and its implications \\
& in pregnancy, and whether their \\
& motivations to conceive were \\
& similar to those of women without \\
& congenital heart disease
\end{tabular}

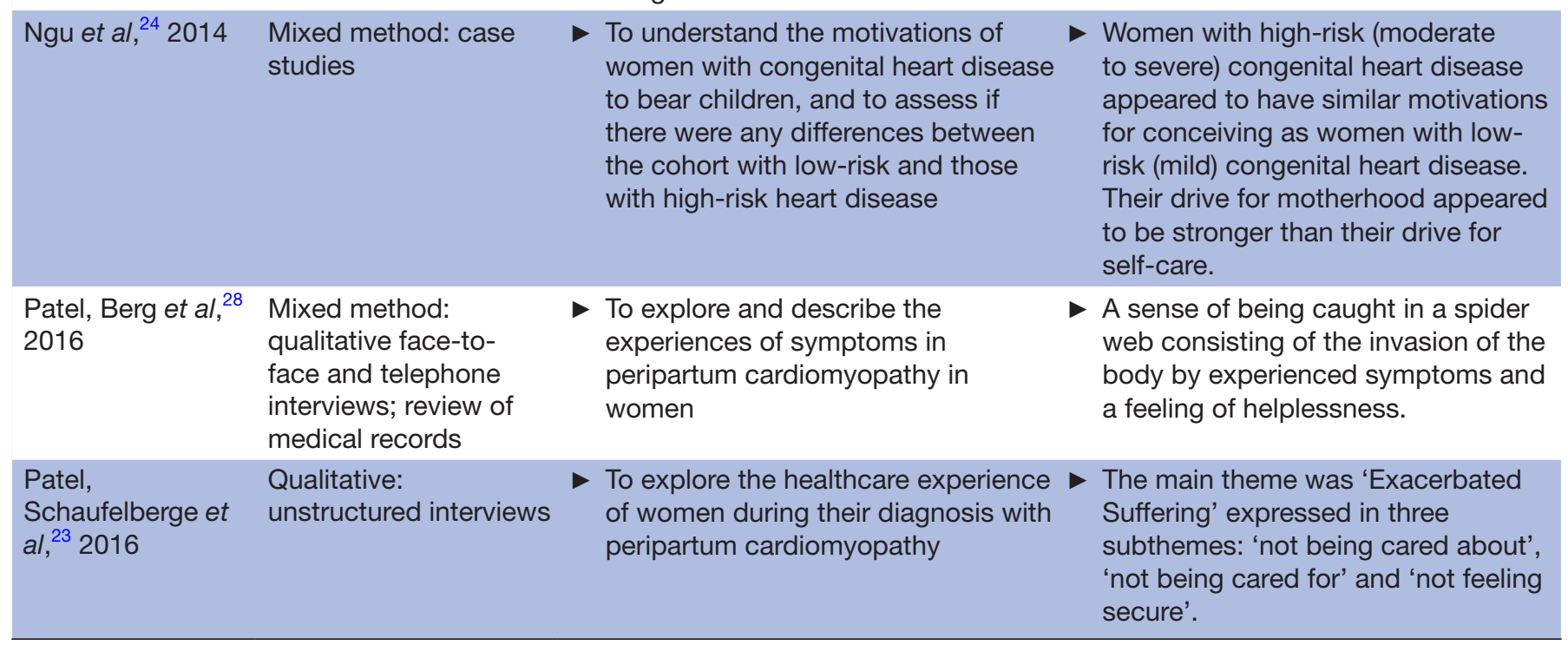

severe than that reported by their clinicians. These women therefore downplayed the seriousness of their condition that was found to be related to a reliance on the care of their health professionals, and a belief that medical and surgical care would result in a successful pregnancy and birth outcome. This distorted view of their condition was also linked to their quality of life which they felt was $\operatorname{good}^{24}$

\section{Social support for decision-making}

A feeling of empowerment and hope provided through social support was clearly demonstrated in several publications analysed in this study. Women using an online support said, 'It is beneficial to know that you are not alone', ${ }^{26}$ 'friendly, open arms' that 'gave me hope ${ }^{26}$ and 'there is always hope'. ${ }^{27}$ Some women shared the positive feeling of being able to talk to someone who could understand them without judgement and to share experiences. Women found peer education to be an important part of managing their life and living with heart failure. ${ }^{26}$ Another woman described the distress of having to face her pregnancy decision-making alone, as she lacked support from her family, who did not want her to take any risks. ${ }^{18}$

\section{Healthcare experiences}

Health information needs

Our study revealed gaps in the understanding of women's health information knowledge or needs by clinicians.
Several women felt that they had received inadequate information from clinicians. Only six of the participants in one study had information about contraception and its relationship to their heart disease. ${ }^{21}$ One woman stated that she was 'shocked' that none of her clinicians had discussed the severity of her condition with her: 'I thought I was completely fine. I didn't know I wasn't supposed to have any more kids' ${ }^{26}$ The need for appropriate information delivery and counselling was highlighted by one women who recounted the time of extreme panic when her doctor delivered her diagnosis: 'With no family present, he told me that I might need a heart transplant and that I was finished being pregnant'. ${ }^{22}$

\section{Responsive care}

Many women felt that they had received supportive care from their healthcare team, were grateful and praised the skills and responsiveness of their clinicians. One woman expressed this by stating that the 'world's elite team was there for me during the labour'. ${ }^{23}$ Another group of 13 women shared how grateful they were to the nurses who brought their newborn babies to the intensive care unit where they were staying, and recognised the separation concerns. ${ }^{22}$ Women also reported feeling 'secure' when provided with the phone number of a cardiac nurse or cardiologist to call if they were worried or had questions. Women valued check-ups as these gave them 'hope'. ${ }^{23}$ Women trusted their clinicians and 


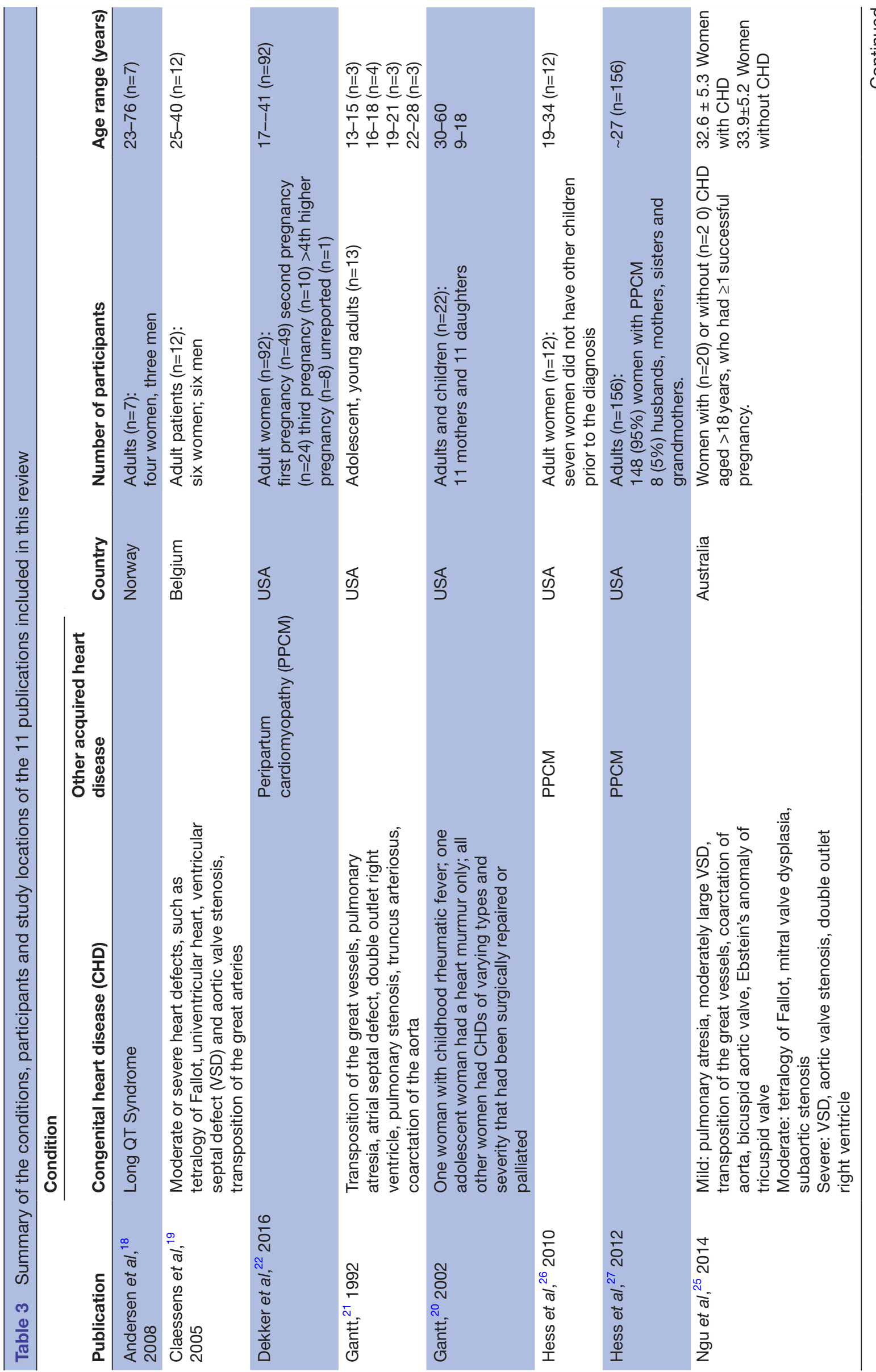




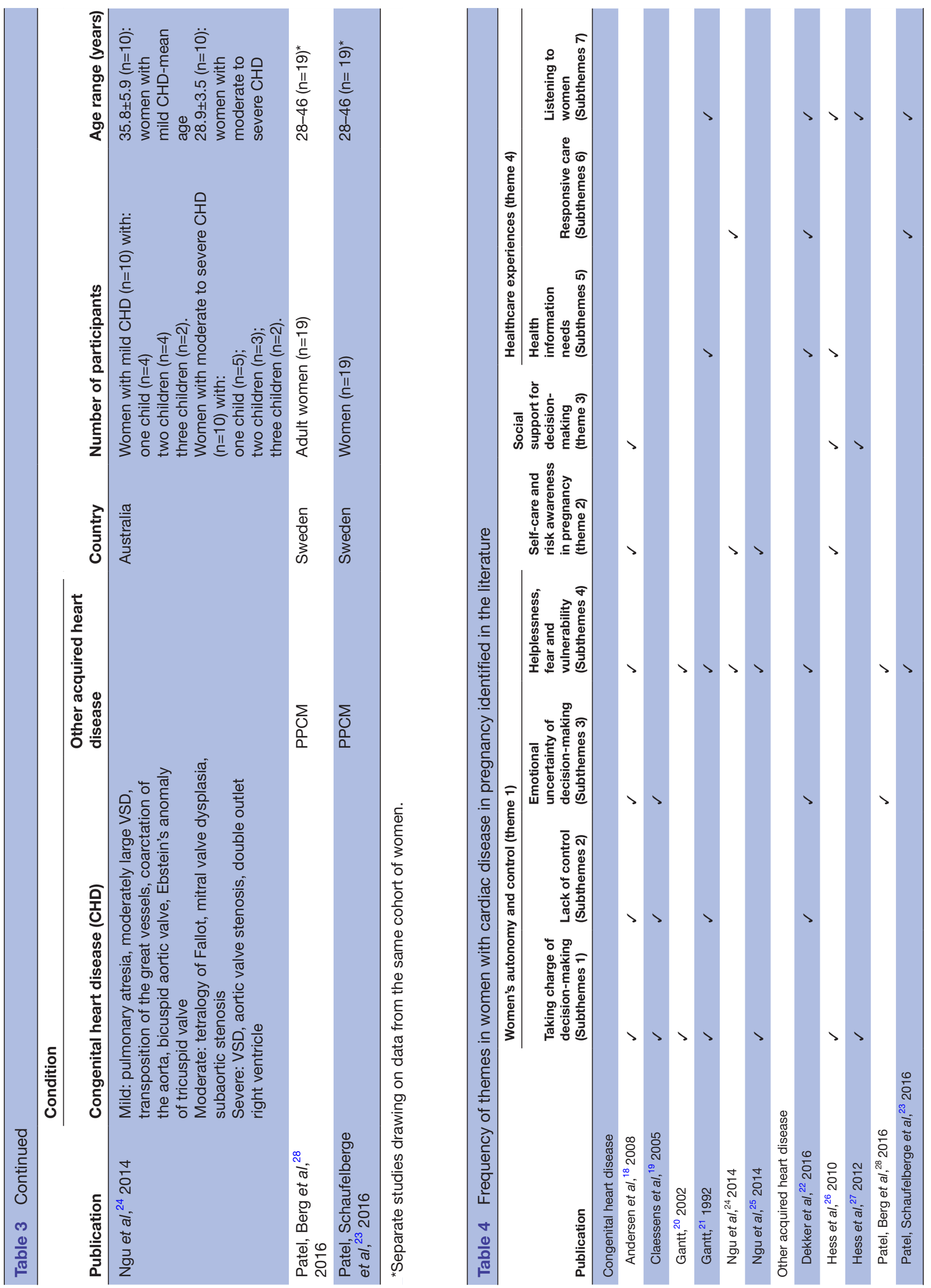

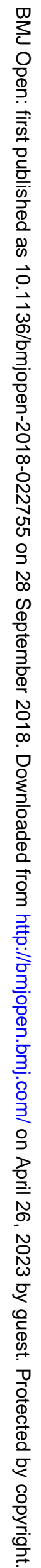


perceived them to be compassionate professionals who would carefully monitor and support them throughout their pregnancy. ${ }^{24}$

\section{Listening to women}

Women commented on situations where clinicians had overly relied on the results of objective tests and careful monitoring throughout their pregnancy to manage their healthcare, rather than listening to them and taking their experiences and feelings into consideration. ${ }^{23}$ Some women reported that their voices were dismissed: 'they didn't seem to care', 22 'they did not listen to me' and 'did not respect my wish.. ${ }^{23}$ As a result, women felt ignored, or misjudged, which caused sadness, insecurity and disappointment in the service provided by their healthcare professionals. Women expressed feeling rejected by clinicians and felt that they were treated like a drug addict', 'like a pile of garbage', ${ }^{23}$ 'like a baby'. ${ }^{21}$ One woman suggested that clinicians learn more about the symptoms of their condition and take the complaints of their patients seriously. ${ }^{26}$

\section{Healthcare facilities and professionals}

There was a paucity of information in the literature regarding the healthcare centres and the specialist skills of their providers to support the needs of women with heart diseases. In Australia, women with congenital heart disease were reported to have received care from cardiologists in a public tertiary hospital ${ }^{24}$ and in private clinics $^{25}$; in south eastern USA, they received care at a large tertiary care centre ${ }^{21}$; and in Norway, they received care at a university hospital. ${ }^{18}$ Women with congenital heart disease had also been recruited through an audit of records at a hospital department of paediatric and congenital cardiology in Belgium ${ }^{19}$ and in another US study, by private paediatricians. ${ }^{20}$ Women only referred to care they had received from both cardiologists and obstetricians in the Australian studies. Although women in the American and Norwegian studies referred generically to their 'doctors' or 'health providers' and nurses were noted in the paper from Belgium, less information was available regarding the health facilities and providers of women with other acquired heart disease from the USA 2226 and Sweden. ${ }^{23}{ }^{28}$ However, women in all studies, except in Hess et $a l^{27}$ referred to cardiologists, obstetricians, nurses ${ }^{22}{ }^{23}$ midwives $^{2328}$ and emergency department staff ${ }^{2327}$ as their healthcare providers. It is difficult to draw conclusions from the findings of this study concerning the different healthcare experiences of women according to their providers and the facilities where they received care. While women with acquired heart disease were more likely to mention the care of cardiologists and obstetricians, as well as describe being listened to by their providers, such descriptions were not available in the corresponding papers that described women with congenital heart disease. ${ }^{24} 25$

\section{DISCUSSION}

This paper reports the first metasynthesis of qualitative research that investigated the experiences of pregnant women with a spectrum of cardiac disease. It provided insight into the continuum of preconception, pregnancy and parenting decision-making of these women and provided evidence to inform new healthcare practices and communication for cardiac care in women with heart disease. Our research shows the struggle women have with gaining autonomy and control over their decision-making during pregnancy, and how this impacts their daily lives and presents challenges to self-care during pregnancy. The level of autonomy and control was the most prevalent theme that came across all cardiac conditions investigated reflecting the need for women-centred care.

Our approach did not enable pooling of results and comparison of data across studies. However, our analysis explained how the studies were related, or dissonant, and compared coding and themes (see table 4). This enabled patterns to be discerned that could be translated into cardiac disease in pregnancy and potentially other rare and chronic diseases in pregnancy. It is possible that our thematic analysis may have led to a loss of detail, particularly in relation to the unique contexts of women lives; however, efforts were made to maintain this in the descriptive part of the analysis to retain the integrity of the original studies. The exclusion of non-English papers may have resulted in an incomplete retrieval of research studies.

\section{Women's autonomy and control}

In five of the studies in our metasynthesis, women identified a lack of understanding of and attention to their existing knowledge by clinicians, as well as their self-reported health status and health needs as barriers to satisfactory care. ${ }^{21-232627}$ While suggestions were made about how shared decision-making could be implemented into cardiovascular care, ${ }^{29}{ }^{30}$ and translated into practice in to national programmes such as the Million Hearts initiative, ${ }^{31} 32$ a gendered approach was not considered nor examined in the unique context of various cardiac conditions in pregnancy.

Clinicians could be better supported to facilitate a woman's active role in decision-making at the point of care by using tailored tools, particularly where a woman's self-care may be affected by downplaying their cardiac disease as found in two studies in the metasynthesis. ${ }^{24} 25$ In these cases, gendered tools that incorporate collaborative deliberation ${ }^{33}$ or conversations between women and clinicians could have been useful.

Elwyn et als 'Talk model' ${ }^{34}$ provides a useful conceptual framework for shared decision-making that enables measurement across four components to facilitate effective communication and its ongoing evaluation between a woman and her clinician. However, women also have a responsibility to contribute to charting a clear path through decision-making by identifying barriers and solutions to their implementation. ${ }^{35}$ Even though the Elwyn 
talk model provides a practical way forward for clinicians and women, it does not consider the steps or processes required for implementation including buy-in at the individual clinician and practice level through guidelines and consensus statements, integration into the workflow and evaluation, ${ }^{29}$ particularly in the context of cardiac disease in pregnancy. ${ }^{12}$

Although the voices of pregnant women with genetic conditions and/or from low, lower-middle and upper-middle-income countries as per the World Bank Atlas definition ${ }^{36}$ were absent from the literature, it is likely that they, too, would struggle to gain autonomy and control over their decision-making and to manage their fears and vulnerabilities for all cardiac conditions.

\section{Self-care and risk awareness in pregnancy}

Consistent with previously published reports, ${ }^{37-40}$ our study revealed little insight into preconception counselling and the advice clinicians provided concerning contraception for women with existing cardiac disease or after a pregnancy, when cardiac disease was diagnosed. In one study, less than $50 \%$ of women with cardiac disease had received any counselling. ${ }^{39}$ We found that the timing of a woman's diagnosis of cardiac disease, and hence her experience, was different depending on the type of heart condition. Most of those with congenital heart disease would have been expected to have knowledge of their conditions, and ideally would have had preconception counselling. However, for those with PPCM, the diagnosis may have occurred late in the pregnancy, meaning that some women would have entered pregnancy without cardiac disease and experienced a very different pregnancy until diagnosed. However, many women with PPCM present postpartum, ${ }^{41}$ and therefore, these women's counselling needs would take into consideration subsequent pregnancies.

Miner et al emphasised the importance of including contraceptive counselling early in adolescence on an 'on-going basis' ${ }^{38}$ Furthermore, the American Heart Association and others provide recommendations regarding prenatal counselling for women and their families with heart disease, as well as counselling in relation to the expectant child that takes into consideration feeding and growth issues, quality of life and long-term care, family stressors and foetal cardiac interventions. ${ }^{1242}$

\section{Social support for decision-making}

The health benefits of social support for pregnant women from their partner, family, friends and those who have experienced similar circumstances are well known ${ }^{43}$ and a significant predictor of health-related quality of life. Other authors have highlighted the importance of peer mentoring for pregnant women with defined health needs to allay fear and anxiety, particularly for women with spinal cord injuries ${ }^{44}$ and patients with cardiovascular disease. ${ }^{46}$ Women in two papers in our study ${ }^{26} 27$ found that online blogs related to their disease were helpful. Other studies found online forums to be supportive for other pregnant women with rare or life-threatening conditions in pregnancy. ${ }^{47}$

\section{Healthcare experiences}

Decision-making tools for healthcare can increase patient participation and improve accurate risk perceptions. ${ }^{48} 49$ For women with heart disease, our recommendation is that women should be engaged in the design of these decision-making tools in consultation with healthcare providers and that an effective communications strategy is implemented that links the opinions of cardiologists, obstetricians, maternal foetal medicine specialists, obstetric physicians and anaesthetists, intensivists, midwives and cardiac nurses ${ }^{50}$ to optimise patient care. This strategy would provide a comprehensive support tool that would console women, allay their fears and build their confidence and resilience through coping and selfcare strategies. Supporting this approach are data from a study by Patel $e t$ al who reported that effective communication led to responsive and tailored care in women who received high-quality care from teams of health professionals. $^{23}$

The American Heart Association emphasises the importance of measuring the self-reported health status (ie, symptom burden, functional status, and health-related quality of life) of patients with cardiac disease as it is not only a necessary component of clinical risk scoring, but consistent with a holistic view of health and the goals of patient-centred care. ${ }^{51}$

\section{CONCLUSION}

Our metasynthesis revealed that there is a need for tailored, responsive care and gendered models to guide shared decision-making and empathetic counselling across the reproductive lifespan for women with cardiac disease. Our findings were consistent with the experiences of women with other non-communicable diseases in pregnancy, such as chronic kidney disease and diabetes ${ }^{5253}$ and similar to studies of non-pregnant women with cardiac disease. ${ }^{545}$ Our study identified opportunities to improve shared decision-making whereby clinicians understand the social context (her family, employment and other responsibilities) of women and their goals, values and preferences for health. Shared decision-making can facilitate effective communication between a woman and her clinician to develop a shared understanding of the problem and generate a mutually acceptable evaluation and management plan.

\section{Author affiliations}

${ }^{1}$ Australian Centre for Public and Population Health Research, Faculty of Health, University of Technology Sydney, Sydney, New South Wales, Australia

${ }^{2}$ Faculty of Medicine and Health Sciences, Macquarie University, Sydney, Australia ${ }^{3}$ Department of Cardiology, Royal Brisbane and Women's Hospital, Brisbane, Queensland, Australia

${ }^{4}$ Australian Centre for Health Service Innovation, Queensland University of Technology, Brisbane, Queensland, Australia

${ }^{5}$ Department of Obstetrics and Gynaecology, Medical School, College of Health and Medicine, Australian National University, Canberra, Australian Capital Territory, Australia 
${ }^{6}$ Department of Obstetrics, Centenary Hospital for Women and Children, Canberra Hospital, Canberra, Australian Capital Territory, Australia

${ }^{7}$ Department of Obstetrics and Gynaecology, Women's and Newborn Services, Royal Brisbane and Women's Hospital, University of Queensland, Brisbane, Queensland, Australia

\section{Acknowledgements The authors would like to thank Sabina Belli for editing this} paper.

Contributors The study was conceived by EAS. EAS and AJD designed the study. YK undertook the literature search and screening with assistance from AJD. YK, AJD and EAS critically appraised the papers. YK and AJD undertook the initial analysis with input from all authors (EAS, KL, MP and WAP). AJD and YK wrote the first draft of the manuscript with input from EAS. All authors contributed to revisions; and editing and approving the final manuscript.

Funding The authors have not declared a specific grant for this research from any funding agency in the public, commercial or not-for-profit sectors.

\section{Competing interests None declared.}

Patient consent Not required.

Provenance and peer review Not commissioned; externally peer reviewed.

Data sharing statement All data used in this meta-synthesis are available in the public domain.

Open access This is an open access article distributed in accordance with the Creative Commons Attribution Non Commercial (CC BY-NC 4.0) license, which permits others to distribute, remix, adapt, build upon this work non-commercially, and license their derivative works on different terms, provided the original work is properly cited, appropriate credit is given, any changes made indicated, and the use is non-commercial. See: http://creativecommons.org/licenses/by-nc/4.0/.

\section{REFERENCES}

1. Creanga AA, Syverson C, Seed K, et al. Pregnancy-Related Mortality in the United States, 2011-2013. Obstet Gynecol 2017;130:366-73.

2. Cantwell R, Clutton-Brock T, Cooper G, et al. Saving mothers' lives: reviewing maternal deaths to make motherhood safer: 2006-2008. the eighth report of the confidential enquiries into maternal deaths in the United Kingdom. BJOG 2011;118 Suppl 1:1-203.

3. Humphrey MD, Bonello M, Chughtai A, et al. Maternal deaths in Australia 2008-2012. Canberra: Australian Institute of Health and Welfare, 2015.

4. Sullivan EA, King JF. Maternal deaths in Australia 2000-2002: Maternal Deaths Sydney: Australian Institute of Health and Welfare, National Perinatal Statistics Unit, 2006.

5. Cliffe S, Black D, Bryant J, et al. Maternal deaths in New South Wales, Australia: a data linkage project. Aust N Z J Obstet Gynaecol 2008;48:255-60.

6. Roos-Hesselink JW, Ruys TP, Stein Jl, et al. Outcome of pregnancy in patients with structural or ischaemic heart disease: results of a registry of the European Society of Cardiology. Eur Heart $J$ 2013;34:657-65.

7. RCOG. Cardiac Disease and Pregnancy. Good Practice. London: Royal College of Obstetricians and Gynaecologists, 2011.

8. Roberts WT, Adamson D. Cardiovascular disease in pregnancy. Obstetrics, Gynaecology \& Reproductive Medicine 2013;23:195-201.

9. Moons $\mathrm{P}$, Bovijn L, Budts W, et al. Temporal trends in survival to adulthood among patients born with congenital heart disease from 1970 to 1992 in Belgium. Circulation 2010;122:2264-72.

10. Chor J, Rankin K, Harwood B, et al. Unintended pregnancy and postpartum contraceptive use in women with and without chronic medical disease who experienced a live birth. Contraception 2011;84:57-63.

11. Lindley KJ, Madden T, Cahill AG, et al. Contraceptive use and unintended pregnancy in women with congenital heart disease. Obstet Gynecol 2015;126:363-9.

12. Canobbio MM, Warnes CA, Aboulhosn J, et al. Management of pregnancy in patients with complex congenital heart disease: a scientific statement for healthcare professionals from the american heart association. Circulation 2017;135:e50-e87.

13. RCOG. Cardiac Disease and Pregnancy Good Practice No 13. London: Royal College of Obstetricians and Gynaecologists, 2011. https://www.rcog.org.uk/globalassets/documents/guidelines/good practice13cardiacdiseaseandpregnancy.pdf.
14. Regitz-Zagrosek V, Blomstrom Lundqvist C, Borghi C, et al. ESC Guidelines on the management of cardiovascular diseases during pregnancy. European Heart Journal 2011;32:3147-97.

15. Thomas J, Harden A. Methods for the thematic synthesis of qualitative research in systematic reviews. BMC Med Res Methodol 2008;8:45.

16. NHS. Critical Appraisal Skills Programme (CASP) making sense of evidence 10 questions to help you make sense of qualitative research London: Public Health Resource Unit, 2006. http://www.casp-uk.net/ casp-tools-checklists. (accessed 12 Jun 2017).

17. Thomas DR. A General Inductive Approach for Analyzing Qualitative Evaluation Data. Am J Eval 2006;27:237-46.

18. Andersen J, Øyen N, Bjorvatn C, et al. Living with long QT syndrome: a qualitative study of coping with increased risk of sudden cardiac death. J Genet Couns 2008;17:489-98.

19. Claessens $P$, Moons $P$, de Casterlé BD, et al. What does it mean to live with a congenital heart disease? A qualitative study on the lived experiences of adult patients. Eur J Cardiovasc Nurs 2005;4:3-10.

20. Gantt L. As normal a life as possible: mothers and their daughters with congenital heart disease. Health Care Women Int 2002;23:481-91.

21. Gantt LT. Growing up heartsick: the experiences of young women with congenital heart disease. Health Care Women Int 1992;13:241-8.

22. Dekker RL, Morton $\mathrm{CH}$, Singleton $\mathrm{P}$, et al. Women's experiences being diagnosed with peripartum cardiomyopathy: a qualitative study. J Midwifery Womens Health 2016;61:467-73.

23. Patel H, Schaufelberger M, Begley $C$, et al. Experiences of health care in women with Peripartum Cardiomyopathy in Sweden: a qualitative interview study. BMC Pregnancy Childbirth 2016;16:386.

24. Ngu K, Hay M, Menahem S. Case studies of the perceptions of women with high risk congenital heart disease successfully completing a pregnancy. Heart Lung Circ 2014;23:811-7.

25. Ngu K, Hay M, Menahem S. Perceptions and motivations of an Australian cohort of women with or without congenital heart disease proceeding to pregnancy. Int J Gynaecol Obstet 2014;126:252-5.

26. Hess RF, Weinland JA, Beebe K. "I am not alone": a survey of women with peripartum cardiomyopathy and their participation in an online support group. Comput Inform Nurs 2010;28:215-21.

27. Hess RF, Weinland JA. The life-changing impact of peripartum cardiomyopathy: an analysis of online postings. MCN Am J Matern Child Nurs 2012;37:241-6.

28. Patel H, Berg M, Barasa A, et al. Symptoms in women with Peripartum Cardiomyopathy: A mixed method study. Midwifery 2016;32:14-20.

29. Hess EP, Coylewright M, Frosch DL, et al. Implementation of shared decision making in cardiovascular care: past, present, and future. Circ Cardiovasc Qual Outcomes 2014;7:797-803.

30. Ting HH, Brito JP, Montori VM, et al. Shared Decision Making. Circulation: Cardiovascular Quality and Outcomes 2014;7:323-7.

31. Lloyd-Jones DM, Huffman MD, Karmali KN, et al. Estimating longitudinal risks and benefits from cardiovascular preventive therapies among medicare patients: the million hearts longitudinal ascvd risk assessment tool: a special report from the american heart association and american college of cardiology. Circulation 2017;135:e793-e813.

32. CMS. Million Hearts $\AA$ : Cardiovascular Disease Risk Reduction Mode Baltimore: U: Centers for Medicare \& Medicaid Services, 2017. https://innovation.cms.gov/initiatives/Million-Hearts-CVDRRM/. (accessed 26 Jul 2017).

33. Elwyn G, Frosch D, Volandes AE, et al. Investing in deliberation: a definition and classification of decision support interventions for people facing difficult health decisions. Med Decis Making 2010;30:701-11.

34. Elwyn G, Tsulukidze M, Edwards A, et al. Using a 'talk' model of shared decision making to propose an observation-based measure: Observer OPTION 5 Item. Patient Educ Couns 2013;93:265-71.

35. AHA, 2017. Overcoming barriers to shared decision making: american heart association; http://www.heart.org/HEARTORG/ Conditions/HeartFailure/Overcoming-Barriers-to-Shared-DecisionMaking_UCM_441939_Article.jsp\#.WacypdFLdnl (accessed 26 Jul 2017).

36. Bank W, 2016. The World Bank Atlas method - detailed methodology: World Bank https://datahelpdesk.worldbank.org/ knowledgebase/articles/378832-what-is-the-world-bank-atlasmethod (accessed 23 Jun 2018).

37. Kovacs AH, Harrison JL, Colman JM, et al. Pregnancy and contraception in congenital heart disease: what women are not told. J Am Coll Cardiol 2008;52:577-8.

38. Miner PD. Contraceptive choices for females with congenital heart disease. Prog Pediatr Cardiol 2004;19:15-24. 
39. Vigl M, Kaemmerer M, Seifert-Klauss V, et al. Contraception in women with congenital heart disease. Am J Cardiol 2010;106:1317-21.

40. Chor J, Oswald L, Briller J, et al. Reproductive health experiences of women with cardiovascular disease. Contraception 2012;86:464-9.

41. Elkayam U. Clinical characteristics of peripartum cardiomyopathy in the United States: diagnosis, prognosis, and management. J Am Coll Cardiol 2011;58:659-70.

42. Lafranchi T, Lincoln P. Prenatal counseling and care for singleventricle heart disease: one center's model for care. Crit Care Nurse 2015;35:53-61

43. Emmanuel E, St John W, Sun J. Relationship between social support and quality of life in childbearing women during the perinatal period. $J$ Obstet Gynecol Neonatal Nurs 2012;41:E62-E70.

44. Bertschy S, Geyh S, Pannek J, et al. Perceived needs and experiences with healthcare services of women with spinal cord injury during pregnancy and childbirth - a qualitative content analysis of focus groups and individual interviews. BMC Health Serv Res 2015; $15: 234$.

45. Tebbet M, Kennedy P. The experience of childbirth for women with spinal cord injuries: an interpretative phenomenology analysis study. Disabil Rehabil 2012;34:762-9.

46. Medina EL, Mesquita CT, Loques Filho O. Healthcare social networks for patients with cardiovascular diseases and recommendation systems. International Journal of Cardiovascular Sciences 2016;29:80-5.
47. Lowe P, Powell J, Griffiths F, et al. Making it all normal: the role of the internet in problematic pregnancy. Qual Health Res 2009;19:1476-84.

48. Stacey D, Bennett CL, Barry MJ, et al. Decision aids for people facing health treatment or screening decisions. Cochrane Database Syst Rev 2014;28:CD001431.

49. Coylewright M, Branda M, Inselman JW, et al. Impact of sociodemographic patient characteristics on the efficacy of decision AIDS: a patient-level meta-analysis of 7 randomized trials. Circ Cardiovasc Qual Outcomes 2014;7:360-7.

50. Hjelmfors L, Strömberg A, Friedrichsen M, et al. Using co-design to develop an intervention to improve communication about the heart failure trajectory and end-of-life care. BMC Palliat Care 2018;17:S19-S20.

51. Rumsfeld JS, Alexander KP, Goff DC, et al. Cardiovascular health: the importance of measuring patient-reported health status: a scientific statement from the American Heart Association. Circulation 2013;127:2233-49.

52. Tong A, Jesudason S, Craig JC, et al. Perspectives on pregnancy in women with chronic kidney disease: systematic review of qualitative studies. Nephrol Dial Transplant 2015;30:652-61.

53. McCorry NK, Hughes C, Spence D, et al. Pregnancy planning and diabetes: a qualitative exploration of women's attitudes toward preconception care. J Midwifery Womens Health 2012:57:396-402.

54. Emslie C, Women EC. Women, men and coronary heart disease: a review of the qualitative literature. J Adv Nurs 2005;51:382-95.

55. Lockyer L. Women's interpretation of their coronary heart disease symptoms. Eur J Cardiovasc Nurs 2005;4:29-35. 